\title{
Psychological therapies for depression with regard to their utility-a review
}

\author{
Deepthi Balla \\ Junior Research Fellow(UGC),Department of Psychology \& Parapsychology, Andhra University, \\ Visakhapatnam, Andhra Pradesh, India
}

\begin{abstract}
Depression is the only treatable but most neglected mental health disorder in the world. Reasons for this negligence could be -unawareness of the danger of this disorder, unawareness of treatment options and expenses for undergoing treatment procedures. In this article, the author searched for empirical findings on the so far experimented psychological therapies for depression in different social settings. In this review, the author discussed about Cognitive Behavior Therapy (CBT) related studies, which are conducted in schools, clinics, internet and Mindfulness based therapies.
\end{abstract}

Key Points: Depression, CBT, Mindfulness based therapies

\section{Introduction}

Depression is a state of experience of hopelessness and helplessness of an individual, that shrinks that individual's ability to lead the life in harmony. Thus a depressed individual prefers to stay alone, sulk in distressful events that happen in his life every day. Thus they feel that past is better than present and always neglect the present and worry about the future. In DSM-IV and ICD-10, explanation of depressive disorders, especially Major Depressive Disorder (MDD), indicates a severe symptom i.e., suicidal ideation. Though it was a treatable disorder, these procedures were not at the reach of depressed individual due to unawareness of the consequences (danger) of this disorder, unawareness of treatment options and expenses for undergoing treatment procedures. Thus the investigator compelled to search the available psychological therapies with regard to their usefulness and relapse prevention.

\section{Method}

AIM: to search the available psychological therapies with regard to their usefulness and relapse prevention. Datagathering :

The investigator searched the electronic database of Pubmed from 2000 to 2013 of May and also have searched google for in-depth study of some research findings. The data was gathered under two headings namely, 'psychological interventions for depression among children and adolescents,' and 'mindfulness therapies'. Total of 47 studies have been gathered in this search. But in view of the aim of this study only 25 were considered for inclusion in the study.

\section{Results And Discussion}

These studies were grouped into the following categories :

1. CBT based studies -

1.1 Clinical setup

1.2 School setup

1.3 Computerized CBT

2. Mindfulness therapies

\section{CBT based studies}

The focus of CBT is to eradicate or at least modify the faulty cognitions which are shaped into negative emotions and thus have become leading causes for negative or maladaptive behavior such as depression.

\subsection{Clinical setup}

Review pointed out the efficacy of CBT when used along with pharmacotherapy.

March J, Silva S, Vitiello B; TADS Team. ( 2006) have evaluated the effectiveness of four treatment options for depression in a randomizes control trial, namely - clinical management with fluoxetine (FLX), CBT, CBT combined(CBT \& FLX -COMB) and clinical management with placebo on adolescents with MDD. After 12 weeks the experimenters found that $\mathrm{COMB}$ was more effective than other treatment options. They gave the figures "of effect sizes at week 12--COMB (0.98) > FLX (0.68) > CBT (-0.03)--combined treatment proved 
superior to PBO on 15 of 16 endpoints, to CBT on 14 of 16 endpoints, and to FLX on 8 of 16 endpoints, whereas FLX was superior to CBT on 8 of 14 and to PBO on 7 of 16 measures ". The investigators concluded that COMB is advised because among the patients who were treated with FLX alone suicidality was found in two measures when compared to other treatment regimes. Pairing FLX with CBT is best as CBT predicted to controlling suicidal behavior among MDD. After week 36 response rate found to be more favorable to combination therapy and suicidality too found to decrease in this COMB group( March JS et al ,2007).

There was a new program rigorously experimented by Lusk P, Melnyk BM(2011) COPE (Creating Opportunities for Personal Empowerment), which showed that brief CBT could be effectively delivered to the anxious and depressed teen ( 30 adolescents) in a few sessions of time limit 30 minutes. This program consists of 15 sessions, each progress from focusing on present problem to developing coping styles, nutrition etc. This COPE found to enhance self-concept and educated self-management skills to these adolescents.

Huber D, Zimmermann J, Henrich G, Klug G. (2012) have conducted a quasi experimental study to examine the long term effectiveness of psychotherapies such as CBT, psychoanalytic and psychodynamic therapies. For this objective, they chose 100 patients and treated them with these three therapies. Their base-line behavior was compared with the follow-up period state of mind after three years of observation using Beck Depression Inventory and Global Severity Index for measuring symptoms, the Inventory of Interpersonal Problems, the Social Support Questionnaire for measurement of social-interpersonal functioning and the INTREX Introject Questionnaire for measuring personality structure. The results provided valuable information that psychoanalytic therapy and CBT differed significantly in terms of social-interpersonal and personality structure measures. The authors noted that psychodynamic therapy was superior to CBT when it comes in reducing depressive symptomatology that was developed by the interpersonal problems. This the authors attributed to the dose-effect.

Cox GR et al (2012) did review of ten studies with regard to efficacy of antidepressant medication and psychological therapies. This review pointed out that psychological therapies are so far superior to antidepressant medication. Their analysis was compiled by the investigator of this review in a table format as shown below :

\begin{tabular}{|c|c|c|c|c|c|}
\hline \multirow[b]{2}{*}{ Criteria } & \multirow[b]{2}{*}{$\begin{array}{l}\text { No. of } \\
\text { studies }\end{array}$} & \multirow[b]{2}{*}{ Cases } & \multicolumn{2}{|c|}{ Statistical findings } & \multirow[b]{2}{*}{ Main outcome } \\
\hline & & & $\begin{array}{l}\text { Odds } \\
\text { Ratio } \\
\text { (OR) }\end{array}$ & $\begin{array}{l}\text { Confidence } \\
\text { Interval (CI) }\end{array}$ & \\
\hline \multirow[t]{2}{*}{$\begin{array}{l}\text { Remission immediately } \\
\text { after post-intervention }\end{array}$} & 2 & 220 & $0.52,95 \%$ & 0.27 to 0.98 & $\begin{array}{l}\text { Anti depressive medication more effective than } \\
\text { psychotherapy; } \\
\text { Remission rates }-67.8 \% \text { of participants in the } \\
\text { medication group and } 53.7 \% \text { in the psychotherapy } \\
\text { group }\end{array}$ \\
\hline & 3 & 378 & $1.56,95 \%$ & 0.98 to 2.47 & $\begin{array}{l}\text { Combination therapy more effective than anti } \\
\text { depressive medication only medication } \\
\text { Remission rates }-65.9 \% \text { of combination therapy } \\
\text { group and } 57.8 \% \text { of medication group }\end{array}$ \\
\hline \multirow[b]{2}{*}{ Suicidal ideation } & \multirow[b]{2}{*}{1} & \multirow[b]{2}{*}{188} & $0.26,95 \%$ & 0.09 to 0.72 & $\begin{array}{l}18.6 \% \text { of antidepressant group, } 5.4 \% \text { of } \\
\text { psychological therapy group }\end{array}$ \\
\hline & & & $1.27,95 \%$ & 0.68 to 2.36 & $\begin{array}{l}\text { After 6-9 months } 13.6 \% \text { of and } 3.9 \% \text { of } \\
\text { psychological therapy group } \\
\text { It means that "suicidal ideation was more in } \\
\text { antidepressant group than psychological } \\
\text { intervention group" }\end{array}$ \\
\hline
\end{tabular}

Merry SN et al (2011)did review of studies done on efficacy of psychological and educational interventions among the fifty-three studies reviewed, these researchers found 16 studies to have clearly defined allocations and procedures. In the brief report of their review, Merry et al concluded that "Both universal and targeted programs were found to be effective in reducing depression rates immediately following the intervention. Targeted interventions remained effective for longer than universal interventions (12 months vs. 3 -9 months)." This was put by the investigator of this review in the following table for clear understanding.

\begin{tabular}{|l|l|l|l|l|l|}
\hline Criteria & \multirow{2}{*}{$\begin{array}{l}\text { No.of } \\
\text { studies }\end{array}$} & Cases & \multicolumn{2}{|c|}{ Statistical findings } & \multicolumn{2}{|c|}{ Main outcome } \\
\cline { 4 - 5 } Risk reduction & & $\begin{array}{l}\text { Odds Ratio } \\
\text { (OR) }\end{array}$ & $\begin{array}{l}\text { Confidence } \\
\text { Interval (CI) }\end{array}$ & \\
\hline immediately & 15 & 3115 & $-0.09 ; 95 \%$ & 0.14 to $-0.05 ;$ & $\begin{array}{l}\text { Intervention is effective when compared to no } \\
\text { intervention }\end{array}$ \\
\cline { 1 - 4 } $\begin{array}{l}\text { within 3 to } 9 \\
\text { months }\end{array}$ & 14 & 1842 & $0.11 ; 95 \%$ & 0.16 to -0.06 & \\
\hline 12 months & 10 & 1750 & $0.06 ; 95 \%$ & 0.11 to -0.01 & \\
\hline
\end{tabular}


Psychological therapies for depression with regard to their utility-a review

\begin{tabular}{|l|l|l|l|l|l|}
\hline 24 months & 8 & 2084 & $0.01 ; 95 \%$ & 0.04 to 0.03 & \\
\hline 36 months & 2 & 464 & $0.10 ; 95 \%$ & 0.19 to -0.02 & \\
\hline
\end{tabular}

Castro MM, Daltro C, Kraychete DC, Lopes J. (2012) in their experimental study on 93patinets with chronic pain found that those patients (43) who are undergoing treatment using CBT showed improvement in realms of depressive symptoms, physical limitations, general state of health and emotional aspects indicating overall improvement in quality of life.

Renaud J, Russell JJ, Myhr G.(2013) in their study on 51 patients diagnosed with MDD were compared for the differences in their levels of avoidance and positive outcome expectancies on a pre and post CBT follow-up. They observed that treatment outcome was significantly good for those with low levels of avoidance and low expectancy of positive outcomes. In simple terms, this study indicated that the willingness and expectancy of positive things on part of the patient are significant factors predictors of success of CBT .

This COPE program as reviewed by Lusk P, Melnyk BM (2013) was started as an educating program by Bernadette MazurekMelnyk, focused on cognitive-behavioral skills building along with developing healthy lifestyles among the youth by modifying their Thinking, Emotions, Exercise, and Nutrition (TEEN)

The COPE program sessions in the words of Lusk P, Melnyk BM (2013) are as followed :

"The first 7 sessions of the 15-session program contain the CBT-based educational content with activities that are delivered in the brief COPE for teen depression and anxiety. The other eight sessions of the COPE TEEN program contain education and skills building activities focused on nutrition, physical activity, and healthy lifestyle behavior change"

\subsection{School based programs for depression}

Gillham JE et al (2012) have evaluated the effectiveness of the Penn Resiliency Program that was conducted on 408 middle school students of age range 10-15 years. This program was carried out by the researchers by taking the help of school teachers, counselors and parents of the adolescents. The researchers employed three conditions namely - Penn Resiliency Program for adolescents (PRP-A), Penn Resiliency Program for adolescents and parents (PRP-AP) and school-as-usual control group(here teachers, counselors played their role). For these three groups, the investigators have screened the adolescents cognitive and behavior factors such as depression and anxiety symptoms, cognitive style, and coping at base-line and post-test after six months of the implementation of the intervention. The investigators found that intervention was found to be less effective for the adolescents grouped with their parents (PRP-AP) when compared to PRP-A. But when compared to the third group, these two groups (PRP-A, PRP-AP) found to be superior in terms of their reduction of depression and anxiety symptoms. The investigators found that the efficacy of the treatment was significantly moderated by the levels hopelessness that these adolescents have. These programs, according to the investigators were useful for adolescents experiencing average to high levels of hopelessness. The investigators suggested the use of CBT by the school teachers and counselors can be effective.

Stallard P, et al (2012) have done their study on 5030 of 12-16 years from eight UK secondary schools to experiment CBT in classroom setting. These experimenters, randomly allotted screened depressed students (1064) into three groups namely -classroom based cognitive behavioral group (392), attention control group (374) and usual school provision group (298). The class room CBT group was trained for improvement in emotion-regulation capacities, coping mechanisms, and thinking styles. This CBT consisted of nine modules and two booster sessions, each lasting about 50-60 minutes and is carried out by trained facilitators and teachers. For the attention control group, the class teacher and two facilitators taught topics related to personal, social, and health education such as sex education, ethical issues, diversity, religion, and citizenship. For the usual school provision normal class activities were followed. After 12 months these students are screened by short mood and feelings questionnaire. It showed that students in classroom based CBT found to be exhibiting more depressive symptoms than school as usual group students. The researchers have discussed the possible reasons as followed :

"........at the 12 month follow-up around two thirds of high risk participants continued to be at risk of depression. However, we observed that this intervention may have a potentially harmful effect compared with usual school provision. The higher rates of depressive symptoms in the intervention group at 12 months may indicate a detrimental effect reflecting limited improvement in mood over time. While the possibility of a harmful effect needs to be acknowledged, higher rates of symptoms may reflect greater self recognition and acknowledgement of existing symptoms of depression and negative thinking styles. Unfortunately our data do not extend beyond 12 months and so the longer term effects of the interventions are not known. None the less, in the short term our results suggest that, compared with no intervention, classroom based cognitive behavioral therapy targeting symptoms of depression was associated with increased levels of depressive symptoms. The possibility of worse outcomes after school based intervention programs has also been found for other mental 
health disorders such as attention deficit hyperactivity disorder, and an improved understanding of the mechanisms underlying possible adverse outcomes merits further investigation."

In conclusion these authors suggest caution and proper evaluation and research before conducting any

CBT intervention in school settings.

\subsection{Computerized / online CBT -}

With the advance of technology, especially increase in ease of using internet, the medical provisions are also made available to the patients online. Some studies have attempted to see the efficacy of CBT provided through online. Some of them are reviewed here.

Ruwaard J, Lange A, Schrieken B, Dolan CV, Emmelkamp P(2012) have explored the possibility and effectiveness of web CBT on 1500 Dutch adults. For this they employed clinical psychology graduates and trained them for the modules. First they have selected the patients using "web-administered self-report questionnaires and a 30-minute semi-structured diagnostic telephone interview.' This web-CBT is designed for common mental health problems such as panic , post-traumatic disorder, depression and burnout. Especially, in the words of the researchers, "Web-CBT for Depression is a 16-week treatment that includes symptom awareness training, structuring of daily activities, challenging of dysfunctional thinking patterns, positive selfverbalization, social skills training and relapse prevention." The sessions of online CBT were maintained through structured e-mails, telephone interviews and giving online assignments of typical CBT techniques. For these 1500 adults, especially with regard to depression, it was found that this WEB CBT has high treatment adherence $(71 \%)$ and follow-up for 1 year showed increase in study attrition. It even showed more than satisfactory improvement and recovery rates ( $71 \%$ and $52 \%$ ). The investigators in this regard pointed out the efficacy of their research as followed :

"We found that effect sizes and recovery rates were comparable to, or somewhat better than, those observed in previous controlled trials, and comparable to those of face-to-face routine practice CBT. Posttreatment reductions of specific and general psychopathology were large (pooled $d=1.4 / 1.2 ; P<.001$ ), about $50 \%$ of the patients recovered, and patient satisfaction was high. Our findings suggest that online CBT may be as effective in routine practice as it is in clinical trials "

Arpin-Cribbie C, Irvine J, Ritvo P (2012) in their web-based study on exploring the effectiveness of CBT for perfectionism and psychological distress found this online CBT was useful in achieving the goal. For this they have assigned 77 post-secondary students, who are perfectionists, to one of the three conditions namely no treatment (control group), general stress management (GST) and online CBT for 10 weeks. The authors found that perfectionism related factors such as anxiety and depression were significantly reduced among the participants treated with CBT online.

Radhu N, Daskalakis ZJ, Arpin-Cribbie CA, Irvine J, Ritvo P (2012) did an experimental study online for assessing web-based CBT for treating maladaptive perfectionism. These investigators thus screened 47 undergraduate students as being maladaptive perfectionists. These students were then assigned to WEB CBT or waist-list group. After 12 weeks of the intervention, these investigators found that perfectionism related components such as anxiety, depression, negative automatic thoughts significantly reduced.

A new program called, Competent Adulthood Transition with Cognitive Behavioral Humanistic and Interpersonal Training (CATCH-IT), was found to be useful in alleviating depression. This program is provided to the depressed teen (participants) in 14 modules of 15 to 20 minutes duration. The participators only have to respond to the online modules which renew their perceptions of an event as a stressful event. Especially these involve 'increasing personal motivation, setting goals, developing good coping strategies, and maintaining strong social support networks'

In the review one online game was found to be specially designed for alleviation of depression. That was SPARX(Smart, Positive, Active, Realistic, X-factor thoughts). An unusual way of use of CBT was performed by Merry SN, Stasiak K, Shepherd M, Frampton C, Fleming T, Lucassen MF. (2012). These researchers used a RPG, an interactive fantasy game called SPARX (i.e., , Positive, Active, Realistic, X-factor thoughts). This game consisted of 7 progressive levels, which deal with recognizing and fighting against GNATs (Gloomy Negative Automatic Thoughts. The researchers, for testing this program's effectiveness have screened 187 students of age range 12 to 19 years, who were aware of English language and are found to be depressed (mild to moderate levels). Again among these 94 were introduced to SPARX intervention and remaining 93 were observed at the school counseling center. The students who have been introduced to SPARX need to start this game by selecting a character (avatar) first and then need to follow the in-game instructions. This game proceeds only after successful completion of a level. For instance, level 1 is cave province: 'finding hope.' In this the players were educated about depression (especially about GNATs) in terms of game instructions. In level 2-ice province: being active, these players were taught about basic interpersonal communication skills. In level 3 volcano province: dealing with emotions in terms of expressing deep emotional wounds is encouraged and finally were introduced with assertiveness training, listening, and negotiation skills.

Level 4-mountain province: overcoming problems, consisted of introducing problem-solving skills 
and cognitive restructuring. Level 5-swamp province: recognizing unhelpful thoughts, consisted of cognitive restricting of depressive thoughts (GNATs). Level 6-bridgeland province: challenging unhelpful thoughts, involved with replacing depressive thoughts with encouraging and positive thoughts. In the final level -7canyon province: bringing it altogether, dealing with distress was taught with the help of mindfulness interventions and concluded the game with encouraging the clients never to hesitate to ask others for help. After these levels were completed by these players, these were screened again for depression and its related psychological problems (such as distress, anxiety, hopelessness, enjoyment etc) and these were compared with the control group ( which was treated at school counseling center) for effectiveness measure. These researchers found that "remission rates were significantly higher in the SPARX $\operatorname{arm}(\mathrm{n}=31,43.7 \%)$ than in the treatment as usual arm $(\mathrm{n}=19,26.4 \%)$ ". It was found that SPARX has been enjoyed by the adolescents and its adherence was very high among this group. These adolescents responded that they would like to introduce this program to their friends too.

\section{Mindfulness based therapies}

Mindfulness therapies focus on building up concentration abilities of an individual towards his or her chi-flow. These usually involve breathing techniques and meditation related techniques. Practicing mindfulness techniques helps one to deal with daily distress well.

Teasdale JD, Segal ZV, Williams JM, Ridgeway VA, Soulsby JM, Lau MA.Source (2000) conducted a study on 145 depressed patients who have currently recovered from their depression to see the effectiveness of Mindfulness Based Cognitive Therapy (MBCT) relapse prevention. They randomly assigned these patients to either usual treatment procedures or only MBCT. The researchers found that patients with more than 3 previous episodes of depression were benefited by MBCT but not the patients with only 2 previous episodes of depression. Geschwind Nicole; et al. (2012) have experimented on depressed adults with previous depressed episodes (from one to 3 or more). These researchers randomly allotted them to intervention group and wait-list group and observed that MBCT is superior to wait-list group for reducing residual depression.

Teasdale JD, Moore RG, Hayhurst H, Pope M, Williams S, Segal ZV(2002) in another study evaluated the efficacy of CT and MBCT and explained these therapies usefulness for patients with different depressive episode history. These researchers explained that CT is useful for residually depressed patients whereas MBCT is for recovered depressed patients.

S. Helen Ma and John D. Teasdale (2004) in a similar study found that MBCT reduced relapse from $78 \%$ to $36 \%$ in 55 patients with 3 or more previous episodes; but in 18 patients with only 2 (recent) episodes corresponding figures were $20 \%$ and $50 \%$. MBCT was most effective in preventing relapses not preceded by life events. Relapses were more often associated with significant life events in the 2-episode group.

Mathew KL, Whitford HS, Kenny MA, Denson LA(2010) studied effectiveness of MBCT over a period of 3 years on 39 participants by allotting them to three groups of increasing time periods observation. For instance, group 1 was observed for one year and group 2 after 2 years and Group-3 is after 3 years. The researchers observed that those who have participated in booster sessions and mindfulness activities found to exhibit less depressive symptoms. They found that MBCT is not useful for those with strong rumination. Thus the researchers encouraged practice of MBCT skills to prevent relapse of depression.

Chiesa A, Mandelli L, Serretti A(2012) have conducted a study to examine the effectiveness of Mindfulness based CBT (MBCT) over psycho-education on a sample of 29 MDD patients without remission.

These were screened with Hamilton Rating Scale for Depression (HAMD). Measures used were Beck Anxiety Inventory, Mindfulness Attention and Awareness Scale, and the Psychological General Well-being Index (PGWBI) at baseline, 4 weeks and 8 weeks. Only 16 of these patients had received either MBCT or psycho education and according to the researchers' observation, MBCT group exhibited decrease in remission of depressive symptoms.

Like CBT utility was found using internet, MBCT was also tested for distance delivery by the researchers Thompson NJ, Walker ER, Obolensky N, Winning A, Barmon C, Diiorio C, Compton MT(2010). They experimented it for epilepsy patients. They grouped these epilepsy patients into intervention group and wait-list group. These two groups were provided MBCT by using telephone or internet in a period of 8 weeks and 16 weeks respectively. These researchers found that MBCT decreased depressive symptoms among the intervention group.

Mindfulness techniques enable the practitioner to focus on the flow of energy and lets him to forget the distress related phenomena. In depression literature a term is widely used for such distress focused thinking i.e, ruminative thinking. Hilt LM, Pollak $\mathrm{SD}(2012)$ did a study where they took 120 youth (average age $=11.51$ ) and induced negative mood using an experiment in which the participants were told to express their reasons to be selected for artists in a program soon to be telecasted. These participants were then made believe to receive comments about their expressions from the already selected judges (pre-recorded messages of 3 people), who give average to mild negative statements about their performance. Now these were allotted to 3 conditions problem-solving (identification of problem, choosing solutions etc), mindfulness (imaging their overloaded 
thoughts to be put into a bubble and letting them fly away) and distraction (listening to prompts). The investigators found that distraction and mindfulness are far better in reducing ruminative behavior which is the underlying symptom of depression.

\section{Conclusion}

After reviewing all these studies, the investigator found that no single therapy is effective than CBT. All other therapies reviewed here indicated that they alone cannot bring the expected intensity of outcome. Thus this review found that medication along with CBT or MBT are only the effective solution for treating depression. This review also found that CBT is useful in many settings such as clinical, school and internet (online). It was found that mindfulness is also delivered through online and is effective. But the point that was observed in this review is that cognitive therapy is the essential ingredient for the effectiveness of CBT and MBCT for treating depression among the targeted people. All the CBT related studies focused on educating the depressed individuals regarding coping skills and problem solving skills whereas the mindfulness based studies focused upon removing ruminating behavior of the depressed individual. One interesting study on CBT use was SPARX. The investigator thus apprehends that depression prevention programs are feasible to be conducted in social settings with much efficacy as in clinical settings.

\section{References}

[1]. Renaud J, Russell JJ, Myhr G.(2013). The association between positive outcome expectancies and avoidance in predicting the outcome of cognitive behavioural therapy for major depressive disorder. The British Journal of Clinical Psychology. Mar; Vol. 52(1):42-52. doi: 10.1111/j.2044-8260.2012.02044.x

[2]. Castro MM, Daltro C, Kraychete DC, Lopes J. (2012). The cognitive behavioral therapy causes an improvement in quality of life in patients with chronic musculoskeletal pain. Arquivos de Neuropsiquiatria. Vol. 70(11):864-8.

[3]. Huber D, Zimmermann J, Henrich G, Klug G. (2012). Comparison of cognitive-behaviour therapy with psychoanalytic and psychodynamic therapy for depressed patients - a three-year follow-up study. Zeitschrift fur Psychosomatis Medizin und Psychotherapie. 2012;58(3):299-316.

[4]. Gillham JE et al (2012). Evaluation of a group cognitive-behavioral depression prevention program for young adolescents: a randomized effectiveness trial. Journal of Clinical Child and Adolescent Psychology. 2012 Sep; Vol. 41(5):621-39. doi: 10.1080/15374416.2012.706517.

[5]. March J, Silva S, Vitiello B; TADS Team. ( 2006). The Treatment for Adolescents with Depression Study (TADS): methods and message at 12 weeks. Journal of the American Academy of Child and Adolescent Psychiatry. 2006 Dec;45(12):1393-403.

[6]. March JS et al (2007). The Treatment for Adolescents With Depression Study (TADS): long-term effectiveness and safety outcomes. Archives of General Psychiatry. Vol. 64(10):1132-43.

[7]. Lusk P, Melnyk BM(2011). The brief cognitive-behavioral COPE intervention for depressed adolescents: outcomes and feasibility of delivery in 30-minute outpatient visits. J Am Psychiatr Nurses Assoc. 2011 May-Jun;17(3):226-36.

[8]. Lusk P, Melnyk B M, (2013). COPE for Depressed and Anxious Teens: A Brief Cognitive-Behavioral Skills Building Intervention to Increase Access to Timely, Evidence-Based Treatment. Journal of Child and Adolescent Psychiatric Nursing. Vol. 26( 1): 23-31. doi: 10.1111/jcap.12017. Retrieved from http://onlinelibrary.wiley.com/doi/10.1111/jcap.12017/pdf

[9]. Chiesa A, Mandelli L, Serretti A(2012). Mindfulness-based cognitive therapy versus psycho-education for patients with major depression who did not achieve remission following antidepressant treatment: a preliminary analysis. Journal of Alternative and Complementary Medicine. Vol. 18(8):756-60. doi: 10.1089/acm.2011.0407. Epub 2012 Jul 13.

[10]. Merry SN et al (2011). Psychological and educational interventions for preventing depression in children and adolescents. Cochrane Database Syst Rev. Vol. 7(12):CD003380. doi: 10.1002/14651858.CD003380.pub3.

[11]. Cox GR et al (2012). Psychological therapies versus antidepressant medication, alone and in combination for depression in children and adolescents. Cochrane Database Syst Rev. 2012 Nov 14;Vol. 11:CD008324. doi: 10.1002/14651858.CD008324.pub2.

[12]. Stallard P, et al 2012). Classroom based cognitive behavioural therapy in reducing symptoms of depression in high risk adolescents: pragmatic cluster randomised controlled trial. BMJ. 2012 Oct 5; Vol. 345:e6058. doi: 10.1136/bmj.e6058.

[13]. Merry, S. N., et al (2011). Research in Brief: Psychological and educational interventions for preventing depression in children and adolescents. Retrieved from http://www.hwdsb.on.ca/e-best/wp-content/uploads/2011/03/RIB-Depression-Prevention-Programs.pdf

[14]. Ruwaard J, Lange A, Schrieken B, Dolan CV, Emmelkamp P(2012).The effectiveness of online cognitive behavioral treatment in routine clinical practice. PLoS One. 2012;7(7):e40089. doi: 10.1371/journal.pone.0040089. Epub 2012 Jul 5.

[15]. Radhu N, Daskalakis ZJ, Arpin-Cribbie CA, Irvine J, Ritvo P (2012).Evaluating a Web-based cognitive-behavioral therapy for maladaptive perfectionism in university students. Journal of American College Health. Vol. 60(5):357-66. doi: 10.1080/07448481.2011.630703.

[16]. Arpin-Cribbie C, Irvine J, Ritvo P (2012). Web-based cognitive-behavioral therapy for perfectionism: a randomized controlled trial. Psychotherapy Research Psychotherapy Research . 2012 Mar. Vol. 22(2):194-207. doi: 10.1080/10503307.2011.637242. CATCH-IT.https://beacon.anu.edu.au/service/website/view/145/1

[17]. Merry SN, Stasiak K, Shepherd M, Frampton C, Fleming T, Lucassen MF(2012). The effectiveness of SPARX, a computerised self help intervention for adolescents seeking help for depression: randomised controlled non-inferiority trial. BMJ 2012; 344 doi: http://dx.doi.org/10.1136/bmj.e2598

[18]. GESCHWIND Nicole; et al.; (2012). Efficacy of mindfulness-based cognitive therapy in relation to prior history of depression: randomised controlled trial. British Journal of Psychiatry, Vol. 201(4), pp.320-325.Retrieved from http://www.sciesocialcareonline.org.uk/profile.asp?guid=B770FFFC-F463-40A5-A910-3EAD39BAE8D2

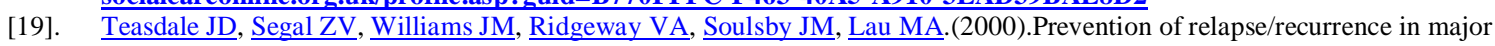
depression by mindfulness-based cognitive therapy. Journal of Consulting and Clinical Psychology. Vol. 68(4):615-23. Retrieved from http://www.ncbi.nlm.nih.gov/pubmed/10965637

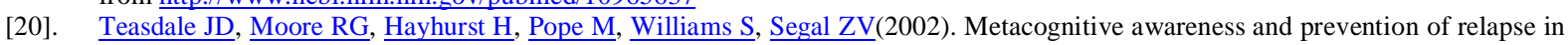
depression: empirical evidence. Journal of Consulting Clinical Psychology. Vol.70(2):275-87. Retrieved from http://www.ncbi.nlm.nih.gov/pubmed/11952186 
[21]. S. Helen Ma and John D. Teasdale (2004).Mindfulness-Based Cognitive Therapy for Depression: Replication and Exploration of Differential Relapse Prevention Effects. Journal of Consulting and Clinical Psychology. Vol. 72(1). Pg.,31- 40. DOI: 10.1037/0022-006X.72.1.31 Retrieved from ftp://ftp.cs.ru.nl/pub/CompMath.Found/teasdale.pdf

[22]. Mathew KL, Whitford HS, Kenny MA, Denson LA(2010). The long-term effects of mindfulness-based cognitive therapy as a relapse prevention treatment for major depressive disorder. Behavioural and Cognitive Psychotherapy. Vol. 38(5):561-76. doi: $10.1017 / \mathrm{S} 135246581000010 \mathrm{X}$

[23]. Thompson NJ, Walker ER, Obolensky N, Winning A, Barmon C, Diiorio C, Compton MT(2010).Distance delivery of mindfulnessbased cognitive therapy for depression: project UPLIFT. Epilepsy\& Behavior. Vol.19(3):247-54. doi: 10.1016/j.yebeh.2010.07.031.

[24]. Hilt LM, Pollak SD(2012).Getting out of rumination: comparison of three brief interventions in a sample of youth. Journal of Abnormal Child Psychology. Vol. 40(7):1157-65. doi: 10.1007/s10802-012-9638-3. 